\title{
Las motivaciones, estructura y usos de los correos electrónicos mediante internet: un estudio multidisciplinar ${ }^{1}$
}

\author{
Graciela Padilla, Dinitrina Semova y Paula ReQueiJo*
}

Propuesto: 14 de abril de 2011

Evaluado: 30 de abril de 2011

Aceptado: 2 de mayo de 2011

(Abstracts y palabras clave al final del texto)

Este artículo constituye un resultado parcial de análisis relativos a la naturaleza y estructura de las presentaciones audiovisuales y verbales, que los usuarios de correo electrónico intercambian mediante el sistema informático de Internet. La base de la investigación es el análisis de contenido, formal, y de usos y motivaciones, además del estudio de los sistemas de transmisión grupal, de 2.000 presentaciones audiovisuales que, mediante programas como PowerPoint, Windows Media Player o con el acceso a YouTube, han sido enviadas, recibidas y difundidas por usuarios españoles de programas de correo electrónico.

La investigación tomó este aspecto en fases desde sus comienzos. El grupo de investigación procedió, en una primera instancia, a fijar el contenido de las 2.000 presentaciones realizando dos tareas: a) una primera, de reparto e identificación de esa cantidad de mensajes, entre los miembros del equipo de la investigación b) una segunda, de control en el análisis de contenido. Aquí, el grupo comprobó que el análisis de contenido realizado por todos los investigadores integrantes de este proyecto era acorde.

Como referencia fundamental, que da nombre al proyecto investigador, se utilizó la Teoría de la Pirámide de Necesidades de Abraham Maslow (1943, 1988). La Pirámide de Maslow representa uno de los arquetipos básicos de la personalidad humana dinámica. Maslow (1988) desarrolla un esquema en el que 7 niveles de

\footnotetext{
* Graciela Padilla (profesora de la Universidad Camilo José Cela) y Dimitrina Semova son doctoras en Ciencias de la Información e investigadoras del Grupo de Investigación Consolidado 940820 Estructuras Comunicativas e Interacciones en los distintos niveles de la Comunicación Interpersonal, dirigido por el catedrático Felicísimo Valbuena de la Fuente.

Paula Requeijo es licenciada en Periodismo, doctoranda y becaria FPU del departamento de Periodismo III; forma parte del mismo grupo de investigación.

1 El presente estudio tiene su origen en una investigación llevada a cabo por el Grupo 940820 Estructuras comunicativas e interacciones en los distintos niveles de la comunicación interpersonal.
} 
necesidad, que son básicamente evolutivos, permiten satisfacer los diversos intercambios con el entorno, desde el nivel fisiológico básico a los niveles superiores como las necesidades de conocimiento e información, estéticas o de autorrealización espiritual.

\section{METODOLOGÍA}

Actualmente, abundan las investigaciones sobre las redes sociales, los sistemas de interacción mediados por los interfaces de usuarios, y los nuevos fenómenos de identidad en los medios digitales. Sin embargo, no son numerosas las investigaciones sobre las presentaciones audiovisuales en el sistema de correo electrónico en la red. Hay algunas investigaciones sobre cómo el uso más popular de Internet es, precisamente, la mensajería y las búsquedas de información (Shah, Mcleod y Yyoon, vid. Bryant y Oliver, 2009: 213).

Siguiendo una muy reciente tendencia de investigación de medios (vid. por ejemplo la investigación de Lampe de 2007 sobre el uso y funciones de conexión y coordinación del capital social de Facebook), hemos recuperado algunas teorías de usos, motivaciones y necesidades, que pautan el análisis de las funciones desempeñadas por estos nuevos medios, como la Teoría de las Necesidades de Abraham Maslow, citada previamente.

\section{RESULTADOS CUANTITATIVOS}

El análisis de 2.000 mensajes, realizados como presentaciones Power Point o como pequeños videoclips y difundidos por email entre numerosos remitentes y destinatarios, pone en evidencia el principal propósito, consistente en intercambiar conocimiento. Al mismo tiempo, gran parte de las presentaciones nos familiariza con ciudades, edificios, paisajes insólitos, con el fin de proporcionar minutos de goce estético. En tercer lugar, se constata que gran parte de las necesidades que mueven a los remitentes de este tipo de mensajes tiene que ver con el desarrollo afectivo del individuo: necesidades de asociación, amistad, compañerismo y pertenencia a un grupo concreto. Como las investigaciones de diversos autores muestran en los últimos tiempos, los entornos mediáticos creados en Internet reemplazan el marco primario de referencia y crean un mundo parasocial esencial en el que el individuo puede percibir al grupo, asociarse con él e incluso, superar sus propias limitaciones sociales previas (Sheek y Birchmeier, 2007).

A continuación, desarrollamos el análisis cuantitativo de las necesidades de cada nivel, primarias o dominantes y secundarias, engendrando una gradación y agrupando las combinaciones más frecuentes. Por una parte, hemos estudiado las funciones sociales y cívicas centrándonos en la diferencia entre este tipo de difusión de valores y la tradicional que hacen otros medios de comunicación. En ello, hemos contribuido a las investigaciones que muestran el equilibrio entre expresión y comunicación personal, y la necesidad de relación social y conexión con el entorno que con- 


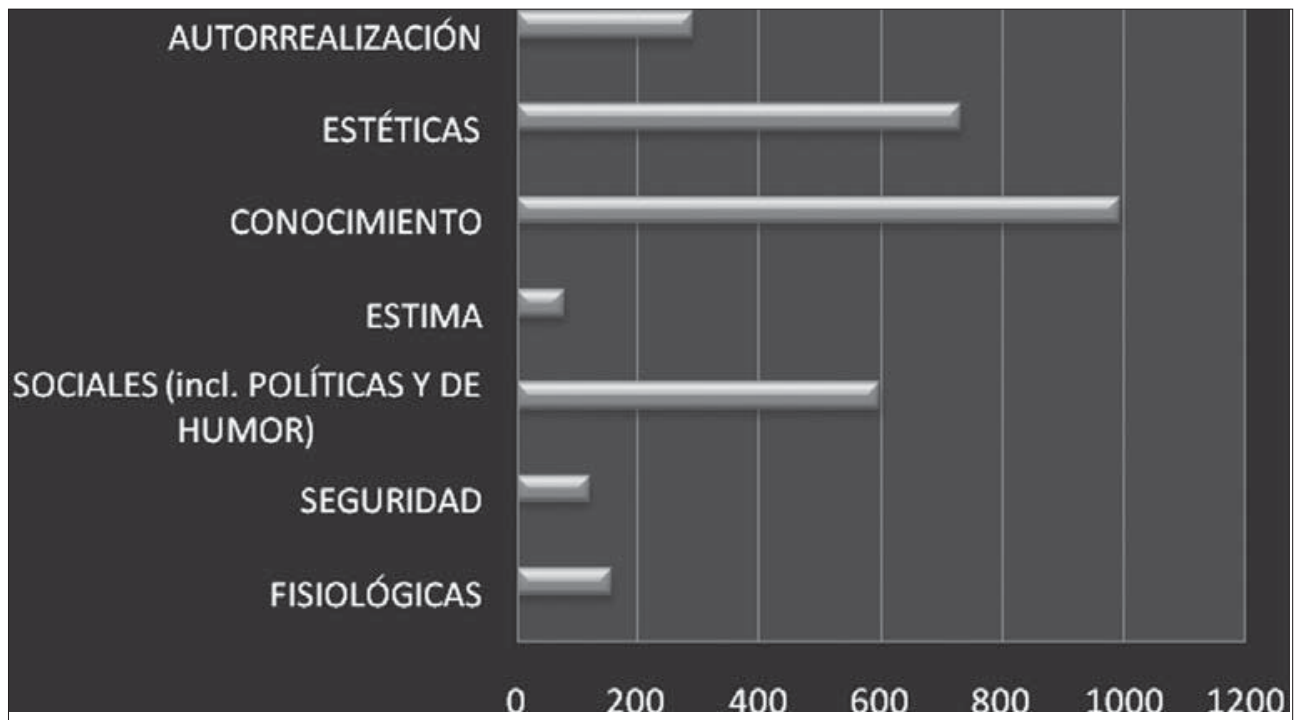

Figura 1.

Necesidades predominantes en las presentaciones según la clasificación de Abraham Maslow (elaboración propia a partir de los resultados de la investigación). El predomino de las necesidades de conocimiento y estéticas se hace patente

siguen los nuevos sistemas de tecnología digital (vid. las investigaciones muy recientes de autores como Caccioppo, Vorderer, Steen, Chan y otros (revisión en Bryant y Oliver, 2009: 534 y ss.).

\section{LA PRIMACÍA DE NECESIDADES DE CONOCIMIENTO Y ESTÉTICAS}

Nada más abordar el análisis de nuestros resultados, se hace patente que los mensajes intercambiados o difundidos por email pueden satisfacer, y de hecho muchos de ellos lo hacen, diferentes necesidades dentro del esquema de Maslow. Este hecho viene a ratificar la idea de multiplicidad en los modos de desarrollo interpersonal, que Maslow indicó con su pirámide. Los datos arrojan una preeminencia de las denominadas necesidades cognitivas, de conocimiento e información, estéticas, o de orden, armonía y belleza, y sociales o de pertenencia (puede verse la distribución de los datos totales en la investigación correspondiente).

El resultado del análisis de los distintos tipos de necesidades, presentes en los mensajes verbovisuales difundidos por email, demuestra la existencia de combinaciones variadas, pero también de algunas constantes, como el hecho de que las necesidades de conocimiento aparecen, en la mayoría de los casos, junto con necesidades estéticas. Esto se puede observar en el gráfico de la página 186. 


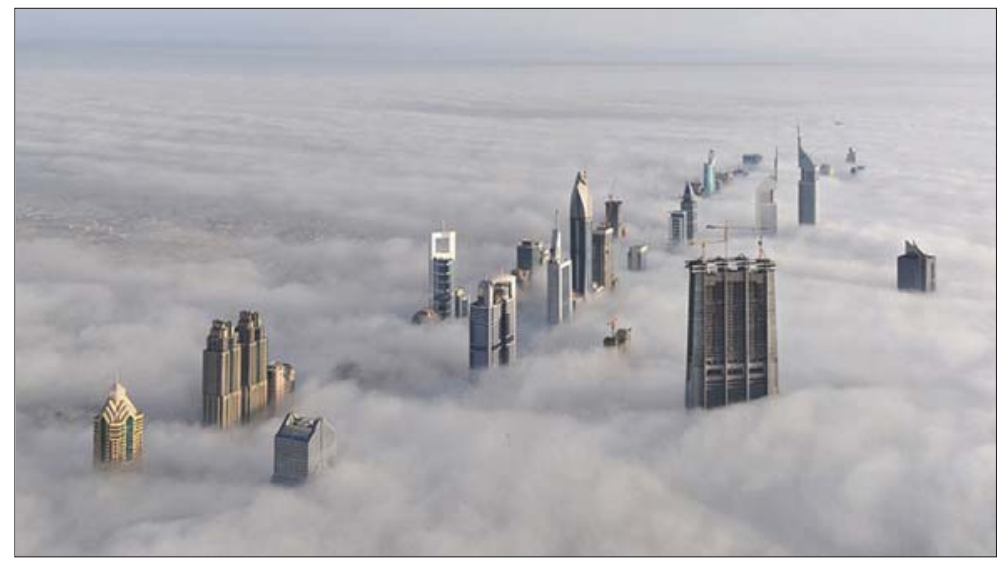

En 1963, un habitante de Derinkuyu (en la región de Capadocia, Anatolia central, Turquia), derribando una pared de su casa-cueva, descubrió asombrado que detrás de la misma se encontraba una misteriosa habitaciónque nunca había visto; esta habitación le llevó a otra, y ésta a otra y a otra... Por casualidad habia descubierto la ciudad subterránea de Derinkuyu, cuyo primer nivel pudo ser excavado por los hititas alrededor del año 1400 a.c.

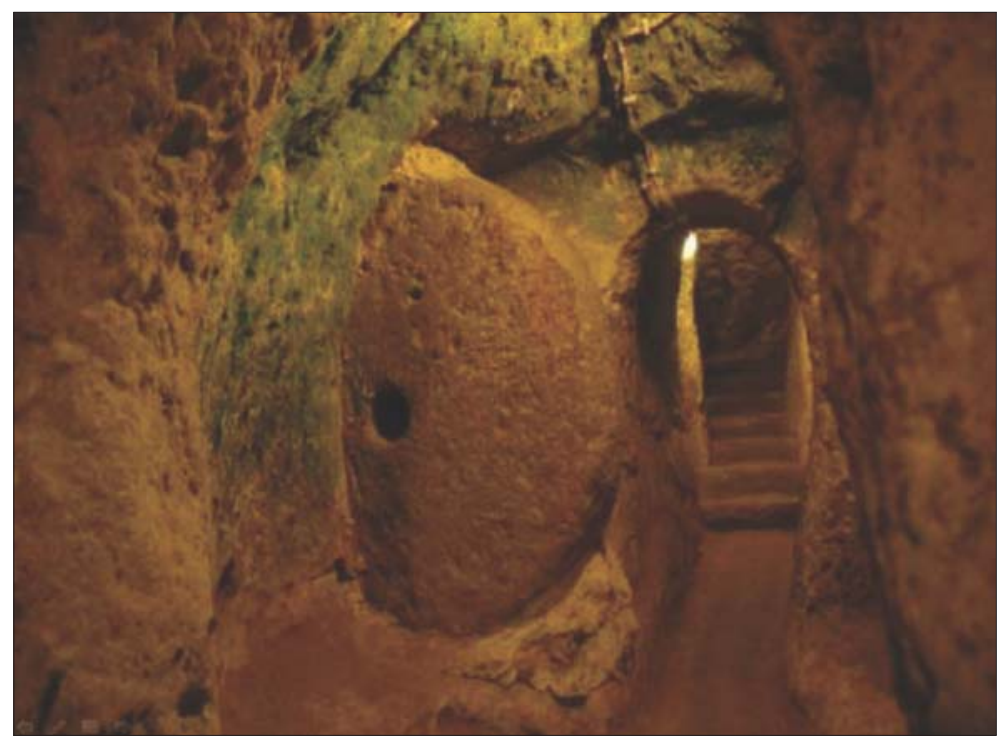


- Los arqueólogos comenzaron a estudiar esta fascinante ciudad subterránea abandonada. Consiguieron llegar a los cuarenta metros de profundidad, aunque se cree que tiene un fondo de hasta 85 metros.

- En la actualidad se han descubierto 20 niveles subterráneos. Sólo pueden visitarse los ocho niveles superiores; los demás están parcialmente obstruidos 0 reservados a los arqueólogos y antropólogos que estudian Derinkuyu.

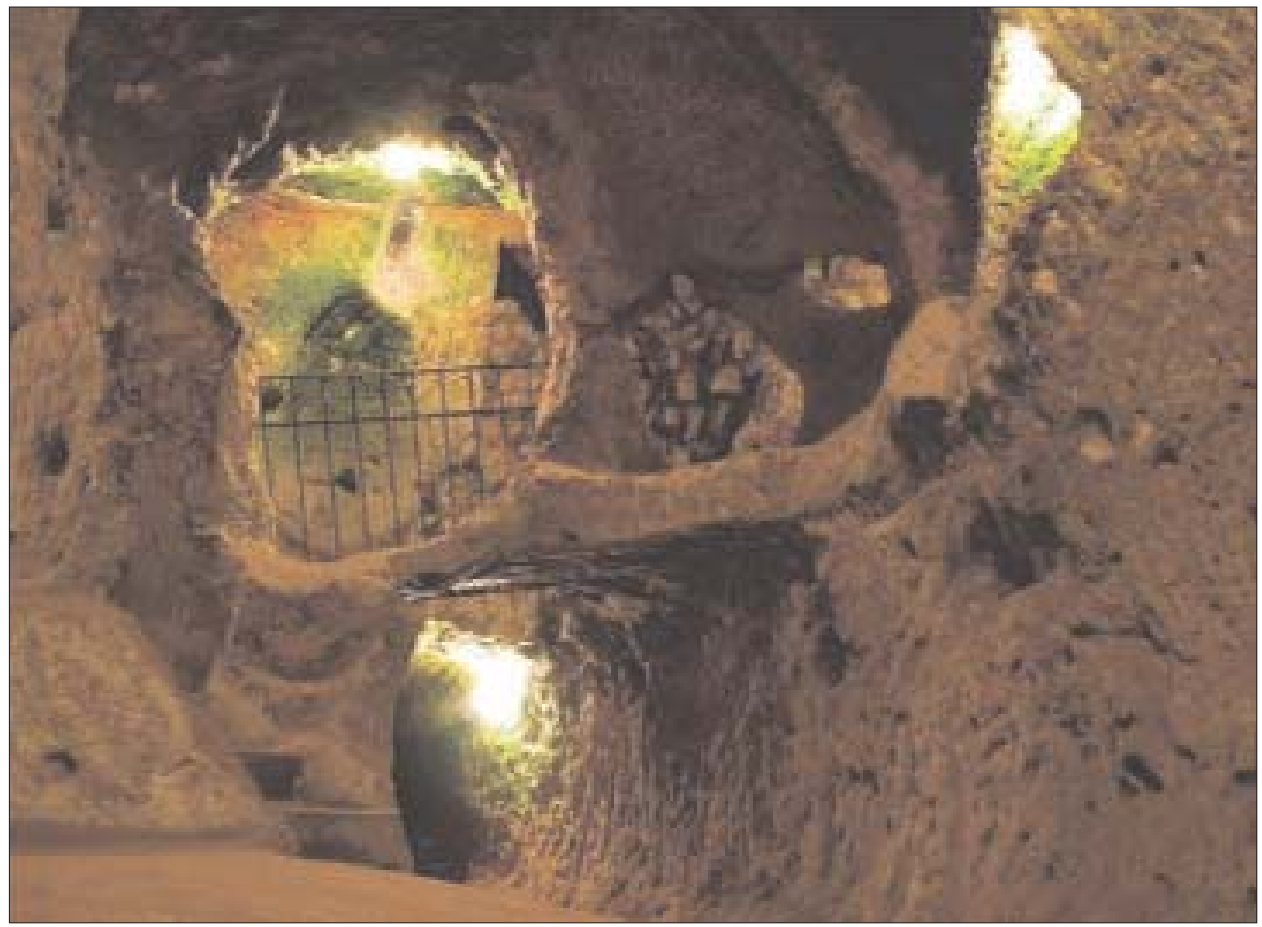

Figura 2

Presentaciones orientadas a doble necesidad: la estética y la información sobre el país de origen, hechos históricos o curiosidades. Se trata de tipos característicos de los estilos predominantes en las presentaciones. 


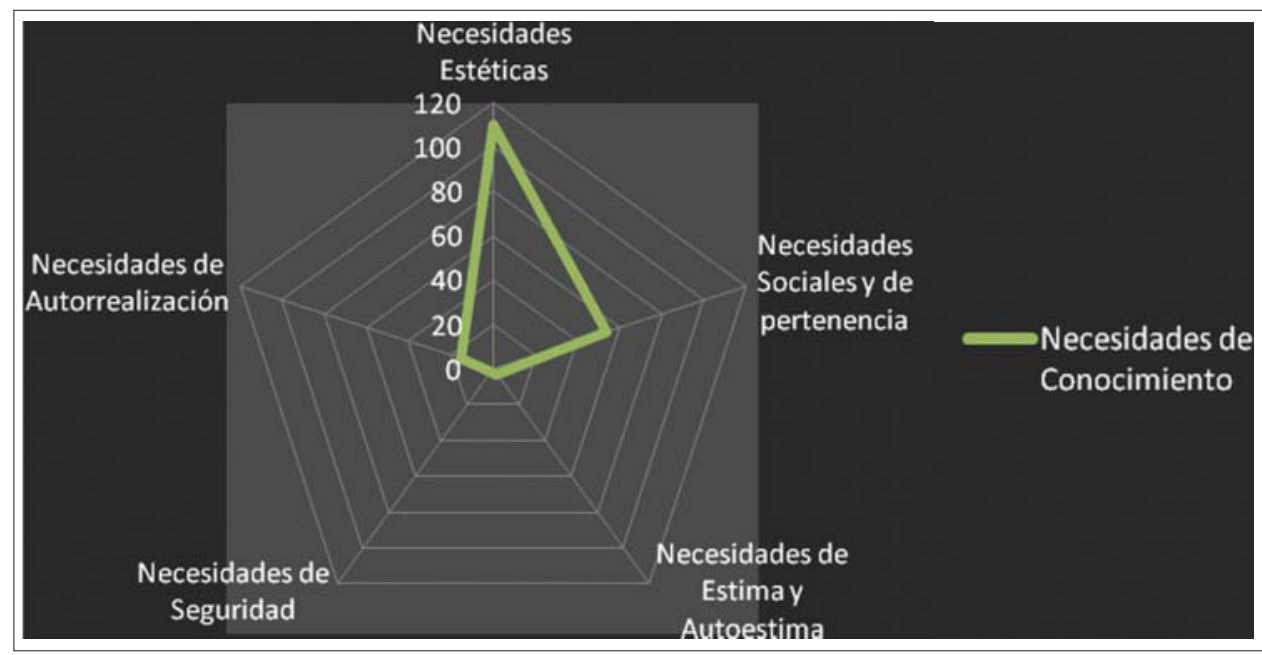

Figura 3

Necesidades cognitivas y metanecesidades. Elaboración propia a partir de los resultados de la investigación. Se aprecia la combinación entre necesidades de conocimiento y las otras necesidades,en cada radio del pentágono. La combinación más frecuente es la estética-cognitiva, así como la social-cognitiva.

El uso de los medios de internet se confirma así, también en su vertiente de correo electrónico, como un uso relacionado con el interés y la curiosidad. Silvio (2006), corrobora esta idea mostrando cómo los procesos de aprendizaje, cognitivos, guiados por el interés y la motivación informativa dominan la Red (vid. Bryant y Oliver 2009: 540).

Las necesidades cognitivas aparecen, a veces, combinadas también con las sociales que experimenta cada individuo y, en casos limitados, con la motivación de crecimiento personal, es decir, con la necesidad de autorrealización. Por otro lado, el afán por el conocimiento puede ostentar vínculos con el sentido de seguridad o con casos en los que se experimenta reconocimiento, aprecio, reputación o atención.

Las siguientes necesidades en la escala de frecuencia e importancia son las necesidades de la cumbre de la pirámide, llamadas de autorrealización. Por debajo de ellas, se sitúan las necesidades de seguridad y de protección frente a peligros o de consejos de vida, las necesidades fisiológicas (que están en el siguiente nivel de frecuencia de aparición) y, en último término, hallamos las de autoestima. Son pocas las presentaciones y mensajes dirigidos a la autoestima personal, la imagen del yo o su comunicación interna; al menos, como alusión directa y explícita.

En un capítulo aparte, desarrollamos cómo la mayoría de las presentaciones tienen una metanecesidad cognitiva, es decir, informan, dan a conocer o ilustran sobre algo, y su finalidad inicial es siempre informativa. Estarían dentro del giro visual del pensamiento contemporáneo (Abril, 2010: 21). Todas se difunden e intercambian a la manera de las narraciones o relatos tradicionales con moraleja o consejo incluidos 
en su contenido (como Benjamin analizó: 1991) y, en cierta medida, conservan rasgos estructurales del relato o lección oral tradicional. Por ejemplo, aparece con frecuencia la estructura en bisociación estudiada por Arthur Koestler (2002: 189-220).

\section{LAS PRESENTACIONES COMO NARRACIONES CON CONSEJO. SIMILITUDES CON EL RELATO ORAL TRADICIONAL}

El profesor Valbuena (2011) ha abordado el análisis de la estructura de difusión y de comunicación grupal que caracteriza estas presentaciones audiovisuales. Como puede verse en su estudio, que se publicará en breve, existen claros sistemas de redifusión de los mensajes a cargo de determinadas figuras que ejercen la tarea reverberante o de rebote cuando se considera que son muy bellos, verdaderos, geniales o buenísimos (como hemos podido comprobar en el análisis de las calificaciones que acompañan o rotulan los emails intercambiados y difundidos).

Es frecuente que la estructura del mensaje de estas presentaciones siga la de una narración o exposición de conocimientos, leyendas o cuentos tradicionales $\mathrm{y}$, en muchas ocasiones, presenta la estructura en bisociación destacada por Koestler para las narraciones creativas (2002: 199 y ss). El acompañamiento musical de fondo, que encontramos en casi todas las presentaciones, apoya esta idea. Éste enmarca directamente en la ficción, dramatización y entorno cinematográfico o creativo el mensaje que se va a recibir. Al igual que en los cuentos o en los romances orales, hay acompañamiento sonoro, que forma parte del envoltorio estético de los mensajes.

La naturaleza de los mensajes audiovisuales estudiados, donde aparecen muchos que satisfacen dos o más necesidades de la pirámide de Maslow simultánea o consecutivamente, es una coincidencia con la estructura bisociativa de los mensajes literarios orales y de los cuentos y narraciones cómicos o burlescos de todos los tiempos, que detectó Arthur Koestler.

Este autor comprobó que el humor es uno de los planos más creativos de acción humana, al mismo nivel que la creación científica o artística. En los tres casos: ciencia, arte y humor, tenemos como rasgo distintivo la multiplicidad de significaciones unidas en una obra o realización humana. Éste es el signo más evidente de la creación: la unión de significados o planos de sentido en una sola pieza u obra, que puede interpretarse o aplicarse a muy distintos contextos o circunstancias. En el relato tradicional, por ejemplo cómico o burlesco, la lógica sigue un camino no lineal sino múltiple y tendente a la explosión de significados múltiples (vid figuras correspondientes 2 y 3), que viene favorecido por la existencia de, al menos, dos significados paralelos del mensaje en cuestión.

La estructura de la presentación en Power Point o el video que acompaña a los emails siguen el mismo itinerario en el que la sorpresa o explosión de significados se dan, con mucha frecuencia, en el estilo cómico. Las presentaciones en Power Point suelen contener giros inesperados, cuando se trata de mensajes humorísticos, como veremos más adelante. En general, es preciso seguir la trama argumental y estar atentos a ella, sin saltar ninguna diapositiva, pues pueden incluir algún giro o aspecto especial del mensaje. 


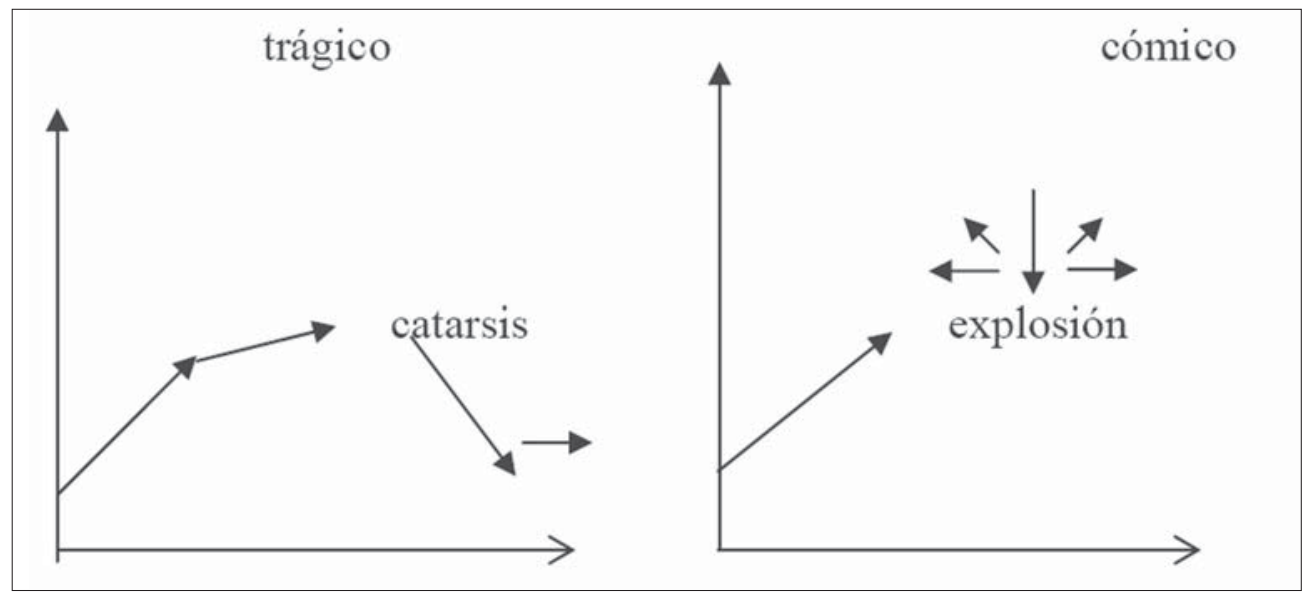

Figura 4

Las dos imágenes muestran el diferente dibujo narrativo del estilo trágico que alcanza una catarsis y luego decae, y el cómico, que conduce a una explosión de significados.

(Fuente: Koestler, 2002: 198 y ss).

Telepizza, que desea?

Magdalenas.... No te jode!

Figura 5

Presentación de humor social o convencional.

En general, observamos la existencia de diferentes planos de significado en una misma presentación audiovisual. Es muy frecuente, por ejemplo, la confluencia de un mensaje estético y a la vez espiritual o metafísico, que circula en dos planos paralelos. También es habitual el cruce del plano estético, con planos humorísticos, sexuales o fisiológicos, que siguen esta estructura, (ver figura 6).

Esta ordenación es característica del relato creativo de la literatura. Así, por ejemplo, en los relatos de humor tradicionales, la trama realista se confunde y coincide con un significado alegórico o implícito que, en ocasiones, emerge para favorecer la confusión y la sorpresa del lector público. Recordemos en El Quijote, por ejemplo, cómo la bisociación se fundamenta en un argumento en principio descabellado - un viejo demente que pasea por la meseta manchega con su tonto servidor-, que trasluce o transmite un significado profundo, patético, tierno, sobre la realidad, sobre la vida y la verdad, con una hondura y universalidad desusadas. 


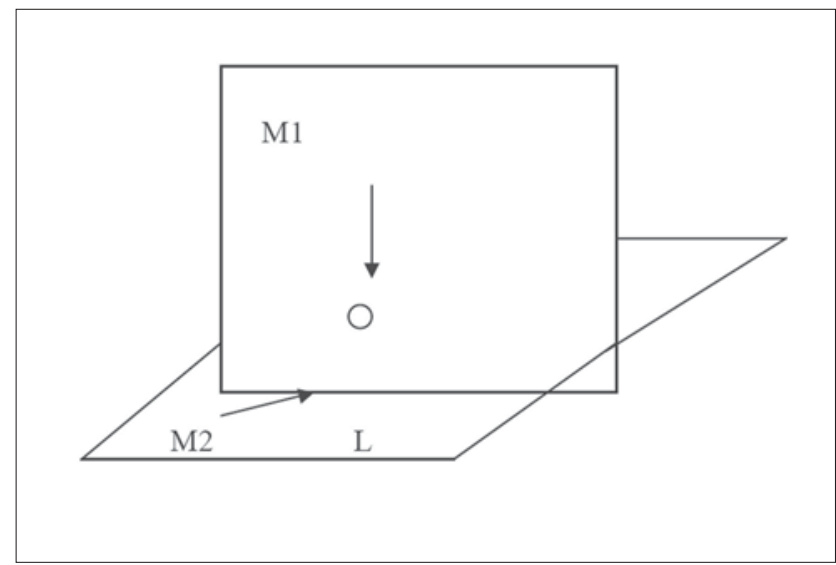

Figura 6

La representación de Koestler muestra dos planos de sentido que forman una intersección mediante la trama narrativa. Los dos planos -cómico y filosófico, estético e informativo, burlesco y filosófico, etc.aparecen a la vez en el mensaje (fuente: Koestler, 2002: 199).

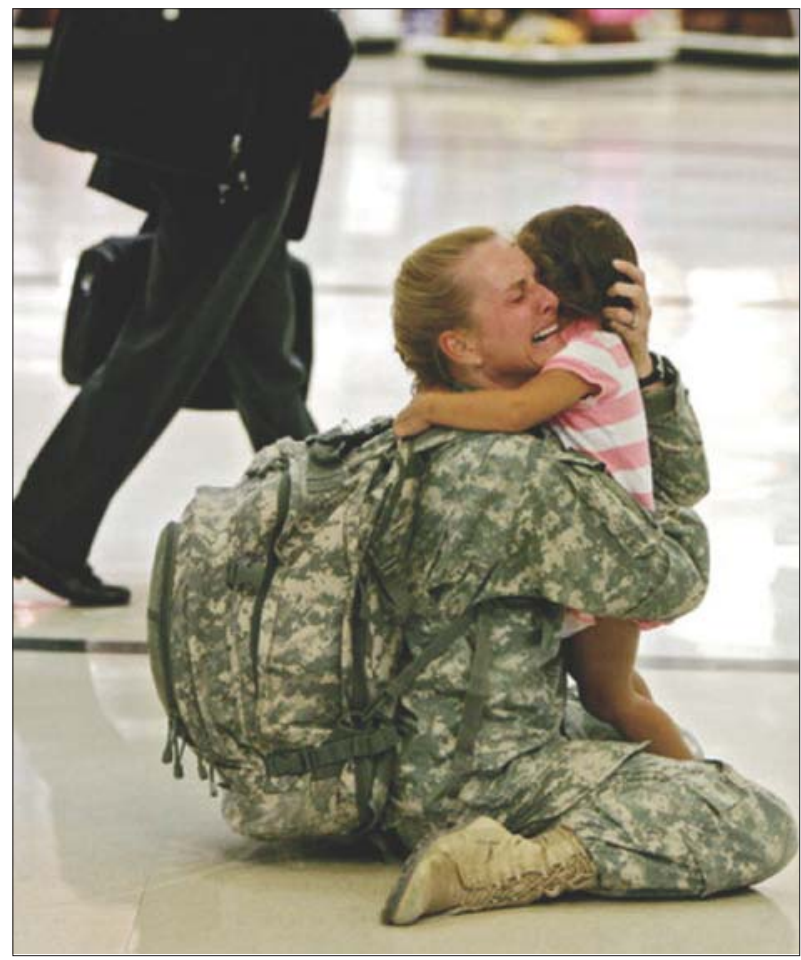

Figura 7

Una foto con varios planos de significación: afectivo-social, estético y político. Se conserva el formato en el que se ha transmitido, como una copia de pantalla. 
Muchas de las obras maestras del arte, la invención creativa o la literatura, conservan y generan una estructura en bisociación o, incluso, en trisociación. Podemos hablar, como hizo Bajtin (1989), de la polifonía de las grandes obras literarias y, desde luego, del haz de significaciones que todo símbolo y mensaje simbólico libera, como afirmaba Mircea Eliade (1988).

Ello supone que podemos "leer" estos mensajes en dobles o múltiples planos, saltando de uno a otro, o descubriendo uno tras el otro, dependiendo del modo en que el autor de los mismos haya dispuesto la estrategia de su comunicación.

En las presentaciones por email seleccionadas y estudiadas abunda el humor. Una importante parte proporcional de los mensajes intercambiados son humorísticos, admitiendo este humor muchas subclasificaciones como, por ejemplo, el humor sexual o físico, el humor social, o el humor político, que "exige un humor de cierta altura intelectual" (Valbuena, 2010: 123).

Otro conjunto de presentaciones se basa en el asombro, sorpresa o impacto. La presentación de email avanza en un sentido y, de repente, sorprende con otro.

También es interesante analizar en qué momento aparece la bisociación de necesidades. Las presentaciones piden o establecen un ritmo de exposición que, habitualmente, se indica solicitando que no se pinche el ratón para no acelerar el desvelamiento progresivo de su impresión. La bisociación sigue en muchas ocasiones la estructura del "gancho" o "golpe" final que inesperadamente cambia el rumbo de interpretación del mensaje.

\section{CONCLUSIONES}

Los correos electrónicos sirven, como las redes sociales primarias, para transmitir modelos y generar apoyo social. Es muy interesante que estos aspectos externos o "alostáticos" (de alostásis, equilibrio con el entorno), se mezclen con aspectos de equilibrio interno o "eudaimónico" (Bernstein y Caccioppo, 2000, citados en Bryants y Oliver, 2009: 534 y ss).

Podemos también notar el característico estilo intimista de estos mensajes, que parecen apelar al yo más profundo del individuo y, con ello, a una redefinición de la relación con el entorno social y con la vida. Así ha sido igualmente visto por autores como Schau y Gilly (2003), quienes indican que los nuevos medios sirven tanto al descubrimiento de la propia identidad como al establecimiento de la relación con los otros. Con ello, las formas de identidad recreadas por estos nuevos sistemas mediáticos proporcionan a las personas la oportunidad de establecer una relación con los demás nueva y diferente. Y como aventuraba Aladro (2009: 107), la comunicación interpersonal forma sistemas informativos que actúan sobre la consciencia individual.

En una parte significativa de las presentaciones que la gente suele enviar por correo electrónico, la belleza de la naturaleza es el tema principal: paisajes insólitos, flora y fauna sorprendentes, etc. Algunas vienen acompañadas de datos pero, aún así, la estética predomina sobre el conocimiento.

No debemos olvidar que en recientes estudios, la motivación estética y la experiencia sensorial de la perfección son poderosos vehículos de aprendizaje. Maslow situó en la cúspide de su pirámide, las motivaciones estéticas, de conocimiento y de 


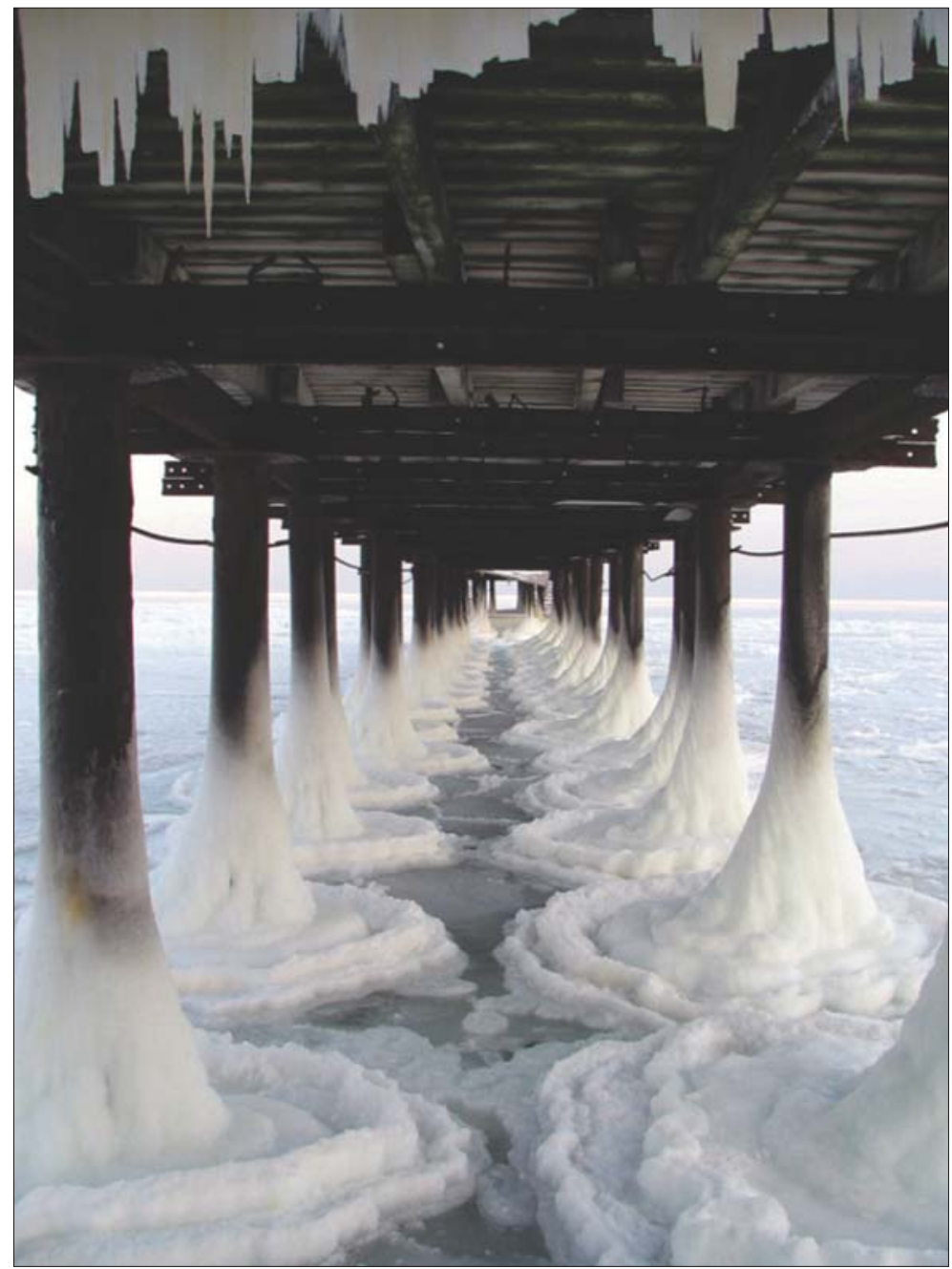

Figura 8

Un ejemplo de bisociación. La foto nos presenta una imagen imposible, en la que el mar helado parece sostener a la ciudad. En realidad, vemos la ciudad a través de la bruma en el muelle.

orden, porque consideraba que estas necesidades superiores podían ejercer una función de atracción hacia el desarrollo personal más elevado. Las investigaciones recientes sobre aprendizaje y sobre creatividad (vid. Amabile y Sternberg: 1998), muestran que la motivación intrínseca, es decir, el placer de hacer algo por el mero hecho de hacerlo, es crucial en la realización perfecta de cualquier actividad y en la generación de experiencias profundas. Muchas de las presentaciones que mezclan estética e información, conocimiento y relación social, muestran la característica complementariedad de los mensajes de las necesidades superiores de la pirámide maslowiana. 
Señalamos el caso de lo que podríamos categorizar como presentaciones de creatividad absoluta. En ellas se desglosan necesidades estéticas y de autorrealización a la vez. Son profundamente informativas porque muestran maneras nuevas de ver las cosas pero, al mismo tiempo, no abandonan el sentido de la adecuación a los modos de recibir mensajes tradicionales, acompañándose de música armoniosa y un ritmo lento de exposición.
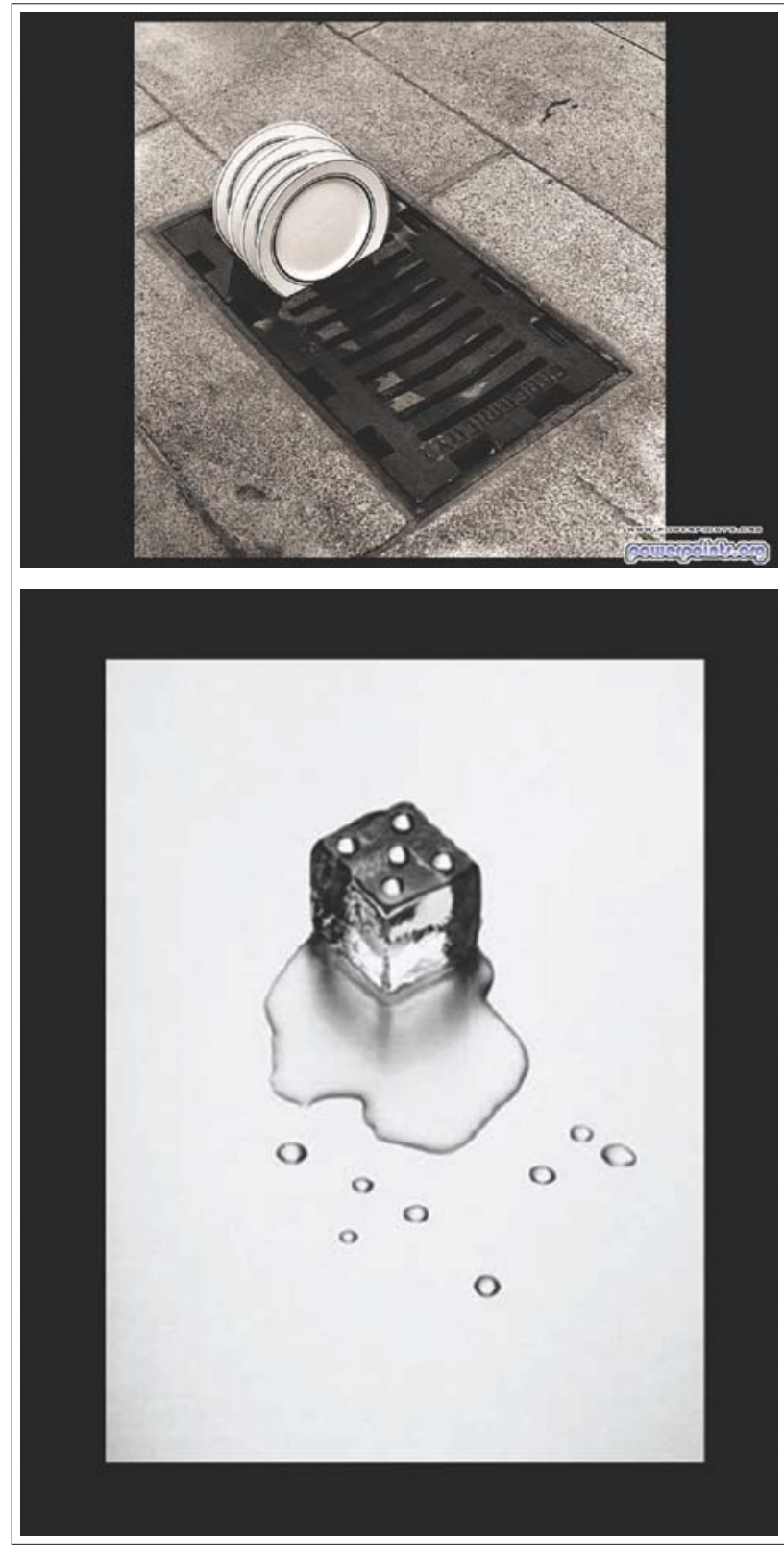

Figura 9

Presentación de la fotografía artística de Chema Madoz. 
En las presentaciones de los correos electrónicos, hay un claro interés por compartir visiones de la vida, experiencias e información esencial para el que difunde los mensajes y para quien los crea o construye. Las estructuras de múltiples planos de significación intentan captar el interés creativo de quien escucha, lee o recibe estas presentaciones. Ese interés es, en muchos casos, gratuito y anónimo, como ocurre con la narración oral tradicional o con la realización artística en las formas tradicionales de muchas culturas. La estructura compleja de estos mensajes nos pone en alerta, pues estamos ante nuevas formas creativas que en principio se desarrollan a partir de formas estereotipadas en programas de usuarios para presentaciones profesionales (PPT). Sin embargo, si la creatividad sigue creciendo en estos sistemas pronto adquirirán autonomía en cuanto a esos formatos fijos.

\section{REFERENCIAS BIBLIOGRÁFICAS}

ABRIL, G. (2010): "Cultura visual y espacio público-político", revista CIC Cuadernos de Información y Comunicación, 15, pp. 21-36.

Aladro, E. (2005): "El Humor como medio cognitivo", revista CIC Cuadernos de Información y Comunicación, 9, pp. 317-327.

(2009): "Espacio Interpersonal, Sistemas de Conducta y Escaladas", en revista CIC Cuadernos de Información y Comunicación, 14, pp. 107-119.

ELIADE, M. (1988): Imágenes y símbolos. Madrid: Taurus.

BAJTIN, M. (1989): Estética y Teoría de la Novela. Madrid: Taurus.

BenJamin, W. (1991): "El narrador", en Para una crítica de la violencia y otros ensayos. Madrid: Taurus.

Bryant, J. y Oliver, M.B. (2009): Media Effects: Advances in Theory and Research. New York/London, Routledge.

HESSE, M. (1954): Science and the Human Imagination: Aspects of the History and Logic of Physical Science. London: SMC Press.

Koestler, A. (2002): "El Arte de la creación. El Bufón", revista CIC Cuadernos de Información y Comunicación, 9, pp. 189-220.

LAMPE, C. (2007): "The benefits of Facebook "friends": Social capital and college student's use of online social network sites", Journal of Computer Mediated Communication, 11(2), art. 4.

Maslow, A. (1943): Motivation and personality. New York: Harper. (1988): El hombre autorrealizado. Barcelona: Kairós.

(1991): Motivación y personalidad.. Barcelona: Díaz de Santos.

(1994): La personalidad creadora. Barcelona: Kairós.

MoyA M. (2007): "Relaciones interpersonales: funciones e inicio".En Morales J.F., Gaviria E., Moya M., Cuadrado I. (coord.): Psicología social. Madrid, McGraw-Hill, pp. 333- 358. 
SchaU, H.J. y Gilly, M.C. (2003): "We are what we post? Self-presentation in personal web space", Journal of Consumer Research, 0(3), pp. 385-404.

SHEEKS, M.S. y BIRCHMEIER, Z.P., (2007): "Shyness, sociability and the use of computermediated communication in relationship development", Cyberpsychology and Behaviour, 10, pp. 64-70.

Sternberg, R. (1998): Creativity. New York, Cambridge U.P.

TuRner J.H. (1988): A Theory of Social Interaction. Stanford, (California): Stanford University Press.

Valbuena, Felicísimo (2010): "El humor en la Comunicación Política", revista CIC Cuadernos de Información y Comunicación, 15, pp. 123-164.

(2011): "Los textos- presentaciones y mensajes en general- que difunden los internautas desde la perspectiva del Análisis Transaccional", Revista de Análisis Transaccional y Psicología Humanista, vol. 64.

\title{
RESUMEN
}

El grupo de investigación 940820 de la Universidad Complutense ha desarrollado una investigación sobre las necesidades y motivaciones presentes en el envío y difusión de los mensajes audiovisuales mediante el sistema de correo electrónico. El objeto de estudio es ver qué funciones, necesidades y usos tienen este tipo de presentaciones mediante el sistema electrónico de correo. Existen antecedentes de investigación de los sistemas en red interpersonal, que reseñamos en el trabajo, pero la investigación de los correos electrónicos muestra todavía una escasa tradición de análisis. La metodología ha sido mixta, utilizando modelos clásicos de los estudios de motivaciones y necesidades, así como aplicando sobre ellos análisis cuantitativo, y estudiando también las redes y sistemas de mediación para la difusión de los mensajes. La intensa implicación de los difusores de los mensajes, la preferencia por necesidades superiores en el contenido de los mismos y la preponderancia del humor, son algunas de las conclusiones principales de nuestro estudio.

Palabras clave: E-mail, internet, usos y gratificaciones, pirámide de Maslow, redes de difusión.

\begin{abstract}
The research group number 940820 of Complutense University has developed an analysis of uses and gratifications involved in audiovisual message-sending through the e-mail. The main goal of the project is to study the functions, the needs and the uses of this type of messages sent by the e-mail system of the Internet. There are precedents in the analysis of interpersonal communicative networks, but the new fields of this communicative activity remain unexplored. The combined methodology of traditional uses and motivations communication theories, a quantitative research and an analysis of the networks of influence and the roles of diffusion, show the importance of the implication of persons, the primacy of superior needs in the messages' content, and the salience of humor are some of the main conclusions of our study.
\end{abstract}

Key words: E-mails, Internet, uses and gratifications, Maslow pyramid, networks of diffusion 


\section{RÉSUMÉE}

L'analyse des présentations adjointes aux e-mails, conduit par le groupe d'investigation de l'université Complutense 940820, veut étudier les fonctions, besoins et les motivations associés à ces types de messages. Cet article aborde les étudies précédents et montre la nouveauté de ce système encore très inconnu dans le contexte des multiples nouveaux services de l'Internet. L'article montre la méthodologie combinée avec des recherches quantitatives et l'analyse culturel qualitative, en résultant l'importance des besoins et finalités esthétiques et cognitives dans ce système, ainsi que la fréquence de l'humeur et de l'implication personnel dans l'utilisation de ce système interpersonnel de communication.

Mots clé: E-mails, Internet, uses et gratifications, pyramide de Maslow, réseaux de diffusion. 